\title{
Comparative efficacy of nalidixic acid and ampicillin for severe shigellosis ${ }^{\star}$
}

\author{
KENNETH C. HALTALIN, JOHN D. NELSON, and HELEN T. KUSMIESZ \\ From the Department of Pediatrics, University of Texas Southwestern Medical School \\ at Dallas, Texas, U.S.A.
}

\begin{abstract}
Haltalin, K. C., Nelson, J. D., and Kusmiesz, H. T. (1973). Archives of Disease in Childhood, 48, 305. Comparative efficacy of nalidixic acid and ampicillin for severe shigellosis. Nalidixic acid is effective in vitro against shigellae including strains multiply-resistant to antibiotics. A comparative study of acute shigellosis in infants and children involved 19 patients treated with ampicillin and 17 treated with nalidixic acid. Stool cultures remained positive longer with nalidixic acid treatment than with ampicillin therapy, and clinical response was slower. The rate of response to therapy was correlated with the serum levels of ampicillin. Though nalidixic acid eliminates shigellae from stools more rapidly than with symptomatic therapy alone, it cannot be recommended for routine treatment of acute shigellosis since it has little effect on the natural course of the illness. In special circumstances when dealing with shigellae that are resistant to ampicillin, tetracycline, and chloramphenicol, nalidixic acid may have a limited use.
\end{abstract}

Double-blind treatment studies in infants and children with severe shigellosis (Haltalin et al., 1967) and in patients with milder disease (Haltalin et al., 1972) have shown the effectiveness of ampicillin compared with placebo treatment. To achieve clinical and bacteriological success in shigellosis, an antimicrobial agent must satisfy two criteria: the infecting strain must be susceptible in vitro, and therapeutic concentrations of drug must be attained in the serum and, more importantly, in the bowel wall (Haltalin et al., 1968a, b. If a patient is treated with a drug to which the infecting strain is resistant, or if an orally nonabsorbable drug is used (Haltalin et al., 1968a; Nelson and Haltalin, 1966), symptoms and faecal shedding persists for periods of time comparable to those observed in placebo-treated patients.

During the last 6 months of 1971 the incidence of ampicillin-resistant Shigella flexneri and Shigella sonnei in our area remained at the same low level of $3 \%$ as reported in our original investigation (Haltalin and Nelson, 1965). In other parts of the world such as England (Davies, Farrant, and Uttley, 1970), and most recently the Washington, D.C. area of the U.S.A. (Ross, Controni,

Received 4 August 1972.

*Supported by grants from the John A. Hartford Foundation and the Sterling-Winthrop Research Institute. and Kahn, 1972), the level of resistance is currently so high that ampicillin is of little or no value for the therapy of shigellosis. During the first 6 months of 1972 the incidence of ampicillin resistance in our area has increased to $28 \%$ for $S$. sonnei isolates and to $10 \%$ for strains of $S$. flexneri. In anticipation of such a rise we have been searching for suitable alternatives to ampicillin. Recently, we have shown that cephaloglycin (Nelson and Haltalin, 1972) and furazolidone (Haltalin and Nelson, 1972) are no better than placebo because adequate absorption of active drug is not achieved.

Nalidixic acid was worth investigating because the available information indicated that virtually all strains of shigellae were susceptible in vitro, and that adequate serum levels of nalidixic acid or of its biologically active metabolite, hydroxynalidixic acid, were uniformly attained. Furthermore, though suitably controlled studies had not been done, several reports suggested that the drug was effective (Moorehead and Parry, 1965; Yu and Chen, 1965; Pesigan and Medado, 1964; Couston, 1966; Fernandez, 1966).

\section{Patients and methods}

Selection of patients. Rectal swab specimens for culture and immunofluorescence studies were obtained 
from infants and children admitted to Parkland Memorial Hospital for severe acute diarrhoeal disease. Within less than 24 hours after admission, patients with a presumptive bacteriological diagnosis of shigellosis were randomly assigned to treatment with nalidixic acid or ampicillin. Excluded from study were those under 1 month of age, those with known drug allergy, and those requiring specific antimicrobial therapy for concurrent infection. Written, informed consent was obtained from the responsible legal guardian of each patient.

Drug therapy. Nalidixic acid suspension was given by mouth in a dosage of $13.75 \mathrm{mg} / \mathrm{kg}$ every 6 hours ( $55 \mathrm{mg} / \mathrm{kg}$ per day) and ampicillin oral suspension was given in a dosage of $25 \mathrm{mg} / \mathrm{kg}$ every 6 hours $(100 \mathrm{mg} / \mathrm{kg}$ per day). The drugs were administered for 5 days (a total of 20 doses). Nonspecific antidiarrhoeal drugs were not prescribed. Symptomatic treatment for fever and phenobarbitone for convulsions were ordered as necessary. Fluid and electrolyte therapy and oral alimentation were given according to ward routine and were similar for both groups of patients. 19 patients were treated with ampicillin and 17 patients received nalidixic acid.

Clinical evaluation. Body temperature and weight, state of hydration, activity, number and character of stools, and other pertinent findings were recorded daily. Provision was made for removal of a patient from the study protocol if the clinical condition was progressively deteriorating.

Laboratory evaluation. Blood culture, complete blood count, urinalysis, serum electrolytes, and blood urea nitrogen were obtained at hospital admission and repeated as indicated. Rectal swabs for culture were collected daily in hospital and at follow-up examinations 1 week after discharge. During the first day of treatment, finger-prick blood specimens for antimicrobial assay and serum inhibition and bactericidal titres were obtained at intervals of $1 / 2,1,2$, and 4 hours after a dose of drug. Additional serum specimens were collected 2 hours after a dose on the second and fifth days of treatment.

Bacteriological methods. Fresh rectal swab specimens were plated onto eosin-methylene-blue agar, salmonella-shigella agar, tergitol-7 agar, and 5\% sheep's blood agar. Initial specimens were also inoculated into tetrathionate broth with added iodine and brilliant green for subculture to brilliant green agar. Subsequent specimens were enriched in GN broth for subculture to eosin-methylene-blue agar and salmonella-shigella agar. Biochemical tests with lysine-iron agar, triplesugar-iron agar, Simmon's citrate, and urea agar were performed on suspected lactose-negative colonies, and agglutination tests were done with commercial shigella and salmonella antisera. Shigella isolates were confirmed and serotyped by the Texas State Department of Health Laboratories in Austin. Organisms isolated during relapse were also sent for reconfirmation and serotyping.
Antimicrobiology susceptibility testing. Plate dilution and tube dilution susceptibility testing were performed with Oxoid sensitivity test broth or agar using bacterial inocula of $10^{3}$ and $10^{6}$ viable bacteria. Twofold serial dilutions of ampicillin or nalidixic acid laboratory reference standard from $80 \mu \mathrm{g} / \mathrm{ml}$ to 0.312 $\mu \mathrm{g} / \mathrm{ml}$ were incorporated in the media. Minimal inhibitory concentrations (MIC) were recorded as the least concentrations inhibiting visible growth after 16 to 18 hours of incubation at $37^{\circ} \mathrm{C}$. Minimal bactericidal concentrations (MBC) were determined with tube dilution testing by subculturing all tubes without visible growth to 5\% sheep's blood agar. In addition, strains isolated from patients treated with nalidixic acid were tested for susceptibility to nalidixic acid by the Kirby-Bauer disc method (Bauer et al., 1966).

Antimicrobial assays and serum inhibition and bactericidal tests. Ampicillin bioassays were performed by the method of Simon and Yin (1970). A micromethod (Nelson et al., 1972) for nalidixic acid assay was developed for these studies. Selected serum specimens were also assayed for nalidixic acid content by fluorimetric and thin-layer chromatographic methods (Clarke Davison, Sterling-Winthrop Research Institute, Rensselaer, New York) to ensure that our bioassay results were reliable. Serum inhibition and bactericidal titres were done by our micromodification of Jawetz's method (Jawetz, 1962).

\section{Antimicrobial susceptibility testing.} Shigella isolates from 19 patients treated with ampicillin were inhibited by ampicillin concentrations from 0.625 to $2.5 \mu \mathrm{g} / \mathrm{ml}$ by tube dilution testing with both $10^{3}$ and $10^{6}$ bacterial inocula. Minimal bactericidal concentrations ranged from 0.625 to $5 \mu \mathrm{g} / \mathrm{ml}$. In 1 patient the infecting strain, $S$. flexneri $2 a$, reappeared on the fourth day of therapy. The MIC of the initial isolate from this patient was $0.625 \mu \mathrm{g} / \mathrm{ml}$, and the $\mathrm{MBC}$ was 1.25 $\mu \mathrm{g} / \mathrm{ml}$. The reisolated strain had an $\mathrm{MIC}$ and MBC of $2560 \mu \mathrm{g} / \mathrm{ml}$ with $10^{6}$ inoculum testing and of $640 \mu \mathrm{g} / \mathrm{ml}$ with a $10^{3}$ bacterial inoculum.

Nalidixic acid susceptibility results of 131 strains are presented in Table I. 80 strains from patients previously studied with shigellosis were tested by plate dilution: 10 of these were also tested by tube dilution. 35 additional strains known to be multiply-resistant to antibiotics were tested by both methods. These strains were studied for resistance transfer factor by Farrar and Eidson (1971). Plate dilution MIC's were $2.5 \mu \mathrm{g} / \mathrm{ml}$ or less for all strains with $10^{3}$ and $10^{6}$ inoculum testing. Tube dilution MIC's tended to run one concentration higher than the plate dilution results. Greater concentrations of nalidixic acid were required for killing, particularly with $10^{6}$ inoculum testing. 
TABLE I

In vitro susceptibility of shigellae to nalidixic acid

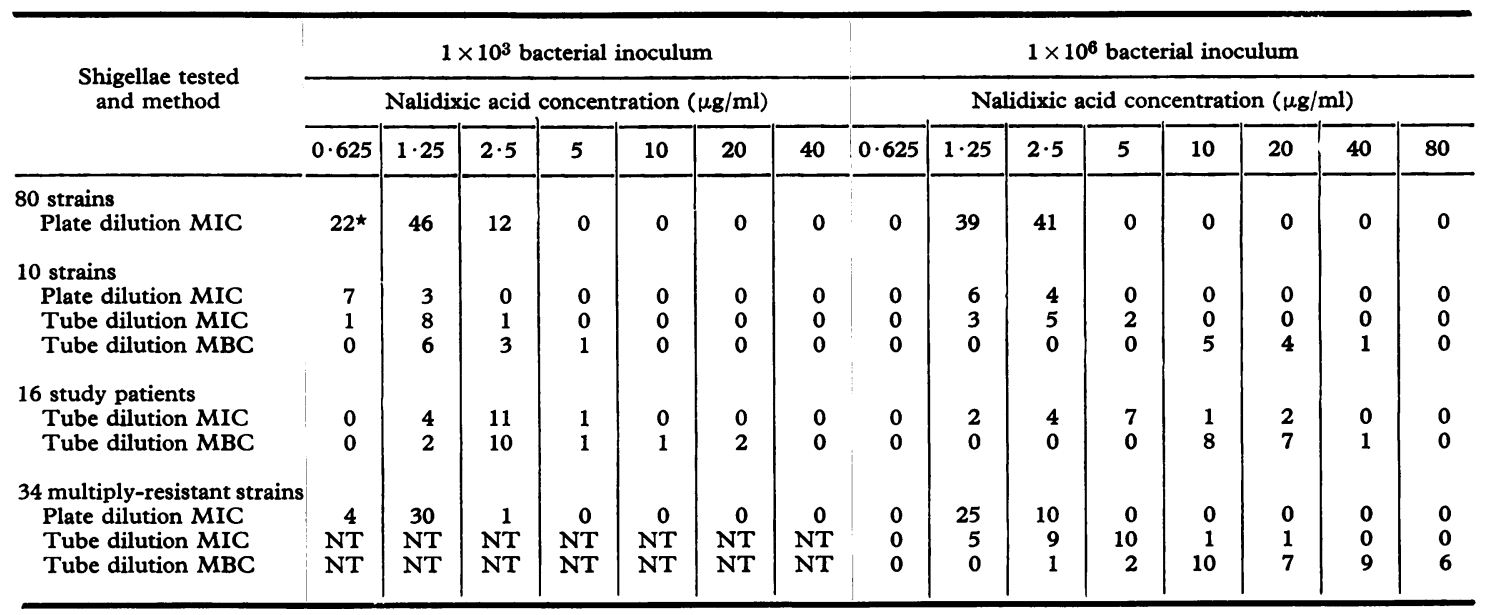

*Number of strains inhibited or killed at the indicated concentration.

MIC, minimal inhibitory concentrations; MBC, minimal bacterial concentrations; NT, not tested.

The shigella strains isolated from 17 patients treated with nalidixic acid were sensitive by KirbyBauer disc testing with zones of inhibition greater than $20 \mathrm{~mm}$. Tube dilution testing of initial isolates from 16 patients treated with nalidixic acid showed that all strains had MIC's of $5 \mu \mathrm{g} / \mathrm{ml}$ or less with $10^{3}$ inoculum testing and that all were killed by $20 \mu \mathrm{g} / \mathrm{ml}$ or less. With the $10^{6}$ bacterial inoculum concentrations from $1 \cdot 25$ to $20 \mu \mathrm{g} / \mathrm{ml}$ inhibited all strains and concentrations up to $40 \mu \mathrm{g} / \mathrm{ml}$ were required for killing. 5 patients had persistence of shigellae in faeces during therapy or relapsed with the same serotype. In one of these patients in vitro resistance emerged. The initial isolate ( $S$. flexneri 3a) had an MIC and MBC of $2.5 \mu \mathrm{g} / \mathrm{ml}$ by $10^{3}$ inoculum testing, and an MIC of 2.5 and MBC of $20 \mu \mathrm{g} / \mathrm{ml}$ against the $10^{6}$ inoculum. The same serotype isolated during relapse had an MIC of $320 \mu \mathrm{g} / \mathrm{ml}$ and an MBC of greater than 320 $\mu \mathrm{g} / \mathrm{ml}$.

Comparability of patients. Selected features of the 2 treatment groups are presented in Table II. $S$. sonnei infection occurred in 7 of 17 patients treated with nalidixic acid and in 5 of 19 patients who received ampicillin. The groups were comparable with regard to duration of illness, severity of disease, and various other clinical parameters.

Bacteriological response (Table III). There was a tendency for faecal excretion of shigellae to persist longer in patients treated with nalidixic acid compared with those who received ampicillin. All cultures were negative by the third day in the group receiving ampicillin and remained negative, with the exception of 1 child who relapsed on the fourth day with an ampicillin-resistant strain. Cultures were still positive after 5 days in 2 patients treated with nalidixic acid, and 3 patients relapsed after completion of 5 days of therapy. These differences were not statistically significant. However, when these observations were analysed according to our arbitrary definition of 'bacteriological failure' (Haltalin et al., 1967), the statistical probability was 0.03 that ampicillin therapy was more effective than nalidixic acid. The average number of days of treatment until faecal shedding ceased was 2.9 days for nalidixic acid and 1.7 days for ampicillin.

Clinical response (Table IV). Diarrhoea did not persist beyond 5 days after start of treatment in any patient in the ampicillin group, but 4 of 17 (24\%) patients treated with nalidixic acid continued with diarrhoeal stools as long as 13 days after entry into the study. 1 patient receiving nalidixic acid was removed from the study after 2 days because of persisting hyperpyrexia, convulsions, and worsening diarrhoea. There were significant differences between the two groups with regard to 'clinical failure', as we have arbitrarily defined it (Haltalin et al., 1967), and to duration of fever and persistence of diarrhoea for more than 5 days. 
TABLE II

Comparability of study groups

\begin{tabular}{|c|c|c|}
\hline & $\begin{array}{l}\text { Nalidixic acid } \\
\text { (17 patients) }\end{array}$ & $\begin{array}{c}\text { Ampicillin } \\
\text { (19 patients) }\end{array}$ \\
\hline $\begin{array}{l}\text { S. flexneri infection } \\
\text { S. sommei infection } \\
\text { Age } \\
<6 \mathrm{mth} \\
6 \mathrm{mth}-2 \mathrm{yr} \\
2 \mathrm{yr}-5 \mathrm{yr} \\
>5 \mathrm{yr}\end{array}$ & $\begin{array}{r}10 \\
7 \\
1 \\
1 \\
4 \\
11 \\
1\end{array}$ & $\begin{array}{r}14 \\
5 \\
2 \\
5 \\
8 \\
8 \\
4\end{array}$ \\
\hline $\begin{array}{l}\text { Race } \\
\text { Black } \\
\text { White } \\
\text { Latin-American }\end{array}$ & $\begin{array}{r}17 \\
0 \\
0\end{array}$ & $\begin{array}{r}13 \\
4 \\
2\end{array}$ \\
\hline $\begin{array}{l}\text { Sex } \\
\text { Male } \\
\text { Female }\end{array}$ & $\begin{array}{r}11 \\
6\end{array}$ & $\begin{array}{r}10 \\
9\end{array}$ \\
\hline $\begin{array}{l}\text { Days of illness before admission } \\
\leq 1 \mathrm{dy} \\
2-4 \mathrm{dy} \\
5-7 \mathrm{dy} \\
\text { Convulsions } \\
\text { Degree of dehydration } \\
<5 \% \\
5-10 \% \\
\geq 10 \% \\
\text { Blood in stools } \\
\text { Mucus in stools } \\
\text { Maximum rectal temperature } \\
\text { before therapy } \\
\leq 37.8^{\circ} \mathrm{C} \\
37.9-38.9{ }^{\circ} \mathrm{C} \\
39{ }^{\circ} \mathrm{C}-40^{\circ} \mathrm{C} \\
>40^{\circ} \mathrm{C}\end{array}$ & $\begin{array}{r}8 \\
7 \\
2 \\
8 \\
3 \\
8 \\
6 \\
11 \\
17 \\
\\
1 \\
3 \\
9 \\
0\end{array}$ & $\begin{array}{r}11 \\
7 \\
1 \\
9 \\
5 \\
9 \\
5 \\
10 \\
19 \\
\\
\\
1 \\
8 \\
4 \\
0\end{array}$ \\
\hline $\begin{array}{l}\text { White blood count } \\
<5000 / \mathrm{mm}^{3} \\
5000-15,000 / \mathrm{mm}^{3} \\
15,000-25,000 / \mathrm{mm}^{3} \\
\geq 25 \% \text { band forms }\end{array}$ & $\begin{array}{c}2 \\
14 \\
1 \\
7 / 16^{\star}\end{array}$ & $\begin{array}{l}5 \\
13 \\
1 \\
8 / 16^{\star}\end{array}$ \\
\hline $\begin{array}{l}\text { Serum sodium concentration } \\
\leq 130 \mathrm{mEq} / 1 . \\
131-144 \mathrm{mEq} / 1 . \\
\geq 145 \mathrm{mEq} / 1 .\end{array}$ & $\begin{array}{r}10 \\
6 \\
0\end{array}$ & $\begin{array}{r}10 \\
8 \\
0\end{array}$ \\
\hline
\end{tabular}

*Denominator represents the number of patients tested.
Serum antimicrobial levels and serum inhibition and bacteridal titres. 67 serum specimens were obtained from patients with $S$. flexneri and 20 specimens from those with $S$. sonnei at varying time intervals during treatment with ampicillin. The serum inhibition and bactericidal titres against the individual patient's infecting organism were compared with actual ampicillin concentrations in Fig. 1. No bactericidal titre was demonstrable against $S$. sonnei in any specimen, and $60 \%$ of specimens $(12 / 20)$ had inhibition titres of $1: 2$. Bactericidal titres were present in $31 \%$ of sera $(21 / 67)$ tested against $S$. flexneri, and $52 \%(35 / 67)$ had inhibition titres of
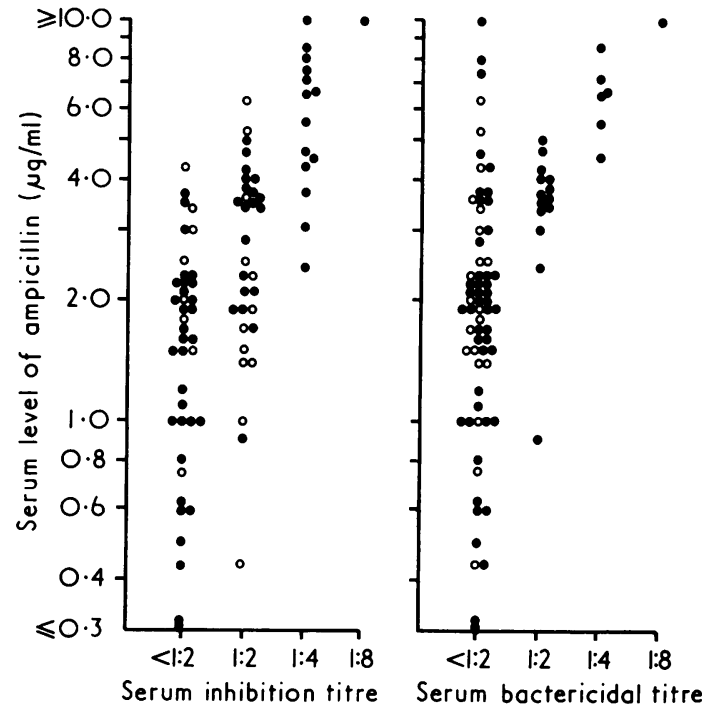

Fig. 1.-Comparison of serum inhibition and bactericidal titres with serum ampicillin concentrations. Specimens from patients with $\mathrm{S}$. sonnei infection, $\mathrm{O}$, and sera from patients with S. flexneri infection,

TABLE III

Bacteriological results of treatment of acute shigellosis with ampicillin or nalidixic acid

\begin{tabular}{l|c|c|c}
\hline \multicolumn{1}{c|}{ Bacteriological observations } & Nalidixic acid (17 patients) & Ampicillin (19 patients) & Statistical significance \\
\hline Culture positive $>48 \mathrm{hr}$ after start of treatment & 3 & 0 & $\mathbf{P}=0 \cdot 0952^{\star}$ \\
Culture positive $>5$ dy after start of treatment & 2 & 0 & $\mathbf{P}=0 \cdot 2158^{\star}$ \\
Relapse & 3 & $\mathbf{P}=0 \cdot 2597^{\star}$ \\
One or more of above 'bacteriological failure' & 6 & 1 & $\mathbf{P}=0.0304^{\star}$ \\
No. of dy until culture negative & 2.9 & $1 \cdot 7$ & $\mathbf{P}>0 \cdot 05 \dagger$. \\
$\begin{array}{l}\text { Mean } \\
\text { Range }\end{array}$ & $1-14$ & $1-3$ & \\
\hline
\end{tabular}

*Fisher exact probability test.

†Mann-Whitney U test. 
TABLE IV

Clinical results of treatment of acute shigellosis with ampicillin or nalidixic acid

\begin{tabular}{|c|c|c|c|}
\hline Clinical observations & Nalidixic acid (17 patients) & Ampicillin (19 patients) & Statistical significance \\
\hline $\begin{array}{l}\text { Diarrhoea }>5 \text { days after start of treatment } \\
\text { Removed from study protocol } \\
\text { One or both of above ('clinical failure') } \\
\text { No. of days diarrhoea after start of treatment } \\
\text { Mean } \\
\text { Range } \\
\text { Days of i.v. fluid after start of treatment } \\
\text { Mean } \\
\text { Range } \\
\text { Days until afebrile after start of treatment } \\
\text { Mean } \\
\text { Range }\end{array}$ & $\begin{array}{c}4 \\
1 \\
5 \\
4 \cdot 0 \\
1-13 \\
3 \cdot 4 \\
2-6 \\
2 \cdot 4 \\
<1-14\end{array}$ & $\begin{array}{l}0 \\
0 \\
0 \\
2 \cdot 7 \\
1-5 \\
3 \cdot 2 \\
2-4 \\
1 \cdot 0 \\
<1-3\end{array}$ & $\begin{array}{l}P=0.0404^{\star} \\
P=0.4722^{\star} \\
P=0.0164^{\star} \\
P>0.05 t \\
\quad N S \\
P<0.05 t\end{array}$ \\
\hline
\end{tabular}

*Fisher exact probability test.

†Mann-Whitney U test.

NS, not significant.

$1: 2$ or greater. There was a rough correlation between the height of titres and the antibiotic content of serum.

A similar comparison from patients treated with nalidixic acid is shown in Fig. 2. 40 specimens were tested against $S$. sonnei and 38 against $S$. flexneri. There were no major differences between the titres against $S$. sonnei or $S$. flexneri serotypes, and there was general correlation between serum inhibition and bactericidal titres and the magnitude of the serum nalidixic acid level.

Relation between antimicrobial absorption and response to treatment. The detailed information concerning antimicrobial dose response curves is presented in a separate communication
(Nelson et al., 1972). Two distinct groups of patients emerged based upon dose responses during the first day of treatment. One group of 9 patients treated with ampicillin was classified as 'poor absorbers' and 8 patients as 'good absorbers'. Peak serum levels occurred 2 hours after a dose in the 'poor absorber' group and in 1 hour in the 'good absorber' category. Peak serum levels in the 'poor absorber' group averaged $1.8 \mu \mathrm{g} / \mathrm{ml}$; the highest single value was $2 \cdot 4 \mu \mathrm{g} / \mathrm{ml}$. By contrast, the mean peak level in the 'good absorber' group was $5.7 \mu \mathrm{g} / \mathrm{ml}$ with the lowest single value $2 \cdot 5 \mu \mathrm{g} / \mathrm{ml}$.

Stool cultures reverted to negative significantly faster in the 'good absorber' group with all 8 patients having negative stool cultures by 48 hours,
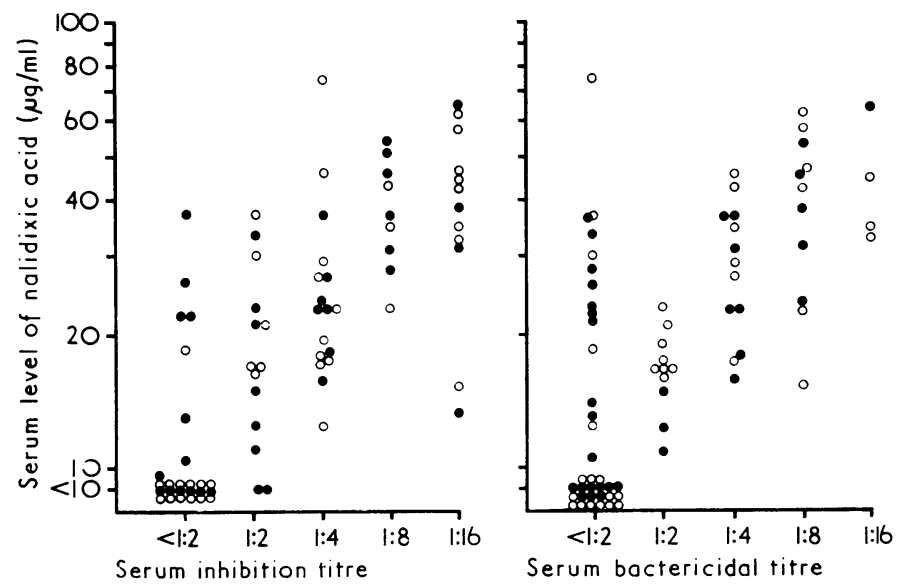

FIG. 2.-Comparison of serum inhibition and bactericidal titres with concentrations of nalidixic acid and its biologically active metabolites. Sera from patients with S. sonnei infection, $\bigcirc$, and from patients with $\mathrm{S}$. flexneri infection, $\bigcirc$. 
whereas 4 of 9 'poor absorbers' required 3 days of treatment to obtain negative cultures $(P=0.0529)$. Similarly, clinical response was better in the 'good absorber' group; none had diarrhoea longer than 3 days after start of treatment. Diarrhoea lasted from 3 to 5 days in 4 of 9 'poor absorbers' ( $P=$ $0.0529){ }^{\star}$ Serum inhibition and bactericidal titres were shown for 6 of 8 'good absorbers', but only 2 'poor absorbers' had an inhibition titre, and none of the 9 had a bactericidal titre.

Patients treated with nalidixic acid also were divided into two patterns of dose response curves. One group had a prompt rise to peak titres in 1 hour, and the other group showed delay in absorption, with therapeutic levels not attained until 4 hours after a dose. Differences in bacteriological or clinical responses were not apparent between those with prompt absorption compared with those in whom absorption was delayed.

\section{Discussion}

The rapidity with which nalidixic acid rids the stool of shigellae appears to lie between the results obtained with ampicillin and those observed with symptomatic therapy alone. Clearing of shigellae occurred more slowly and bacteriological relapses were more common with nalidixic acid therapy than with ampicillin treatment. These differences, however, only attain statistical significance when they are combined and analysed according to our definition of bacteriological failure. If the bacteriological response obtained with nalidixic acid is contrasted with that seen in placebo-treated patients, it becomes clear that nalidixic acid is capable of shortening the duration of faecal excretion of shigellae. A placebo group was not included in the present study because we concluded in an earlier study that placebo therapy of children in hospital for severe shigellosis can no longer be justified (Haltalin et al., 1967). The patients treated with nalidixic acid in the present study had comparable clinical characteristics to those treated previously with placebo and, thus, some comparisons can be made. $75 \%$ of placebo-treated patients excreted shigellae in their stools for more than 48 hours after treatment was begun, and the average time until stool cultures reverted to negative was 5 days. The same observations in the patients receiving nalidixic acid were $18 \%$ and 2.9 days.

Emergence of strains resistant to nalidixic acid during therapy has been described in urinary tract infections (Barlow, 1963). We anticipated that this would be less likely to occur in treatment

^Fisher exact probability test. of shigellosis because of the brief period of therapy. However, a resistant population of shigellae did develop in 1 of the 5 patients in whom bacteriological relapse occurred. Similarly, resistance emerged in the ampicillin-treated patient who relapsed; this is the first time that we have encountered this situation with ampicillin. The rapid emergence of a highly ampicillin-resistant strain after 3 days of treatment suggests that an ampicillinresistant clone may have been present initially and not selected for susceptibility testing.

Clinical response of patients treated with nalidixic acid was significantly inferior to that observed with ampicillin therapy. Diarrhoea continued for more than 5 days in almost $25 \%$ of patients treated with nalidixic acid, but in no patient in the ampicillin group. In addition, fever persisted for a significantly longer period with nalidixic acid than with ampicillin treatment. Persistence of diarrhoea was not likely to have been due to a side effect of the drug. In 3 studies of patients receiving nalidixic acid for urinary tract infection, only 4 of 319 patients developed diarrhoea (Carroll, 1963; Thompson and Rae, 1964; Akbari et al., 1964). The slower clinical response in the nalidixic acid group may have been related to the delayed effect of nalidixic acid in ridding the intestinal tract of shigellae. A comparison of clinical responses between the patients receiving nalidixic acid and the previously reported placebo group shows the average duration of fever to be the same (Haltalin et al., 1967). Diarrhoea ceased more rapidly with nalidixic acid than it did with placebo, but the difference was not statistically significant.

The difference in serum inhibition and bactericidal activity between $S$. flexneri and $S$. sonnei strains from patients treated with ampicillin may be due to the fact that $S$. sonnei strains are less susceptible to ampicillin. Most strains of $S$. flexneri are inhibited by $1.25 \mu \mathrm{g} / \mathrm{ml}$ or less of ampicillin, whereas many $S$. sonnei strains require 2.5 or $5.0 \mu \mathrm{g} / \mathrm{ml}$ for inhibition. This difference in relative susceptibility of $S$. sonnei and $S$. flexneri strains was not seen with nalidixic acid, which correlates with the observation that serum inhibitory and bactericidal titres in patients on nalidixic acid tended to be similar for the two groups.

There was a significant correlation between the height of the ampicillin serum concentration and the clinical and bacteriological responses to therapy. Patients who showed relatively poor absorption of ampicillin were slower to respond to treatment. The peak serum level during the first day of treatment was below the in vitro MIC of the organism in some cases. By the second and third day of 


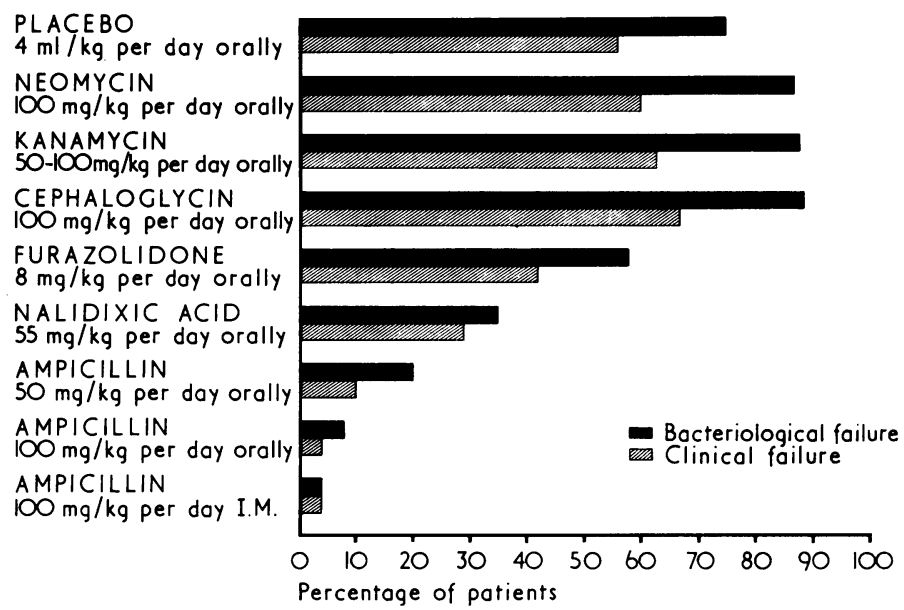

FIG. 3.-Summary of bacteriological and clinical failure rates with placebo and various antimicrobial agents in infants and children in hospital with shigellosis in Dallas. In all cases illness was due to shigellae that were susceptible in vitro to the drugs studied.

treatment the 'poor absorbers' by and large were achieving serum levels sufficient to inhibit the infecting strains of shigella.

By contrast, the patients who had profound delay in absorption of nalidixic acid showed no differences in the duration of positive stool cultures or in the duration of diarrhoea when compared with the group who showed prompt absorption with high blood levels of nalidixic acid. The failure to show clinical differences between the two groups with prompt and delayed absorption perhaps is explained by the fact that, though there was marked delay in absorption, the group of 'delayed absorbers' reached blood levels of nalidixic acid sufficient to inhibit shigellae within 4 hours after a dose.

The importance of adequate serum levels of ampicillin shown in this study fits with our previous observations that intramuscular ampicillin is as effective as the oral preparation in eliminating shigellae from the stools, and more effective in producing rapid clinical response (Haltalin et al., $1968 \mathrm{~b}$ ), and that orally nonabsorbable drugs are ineffective (Haltalin et al., 1968a). Consideration should be given to the importance of adequate serum and tissue levels of ampicillin when initiating therapy. To ensure the best possible therapeutic response, intramuscular or intravenous ampicillin administration is preferable for severely ill patients.

We conclude from this study, and from comparisons with our earlier studies, that nalidixic acid is inferior to ampicillin for treating severe shigellosis when the infecting bacteria are susceptible to both drugs. The bacteriological and clinical failure rates observed in our studies of patients treated in hospital with various drugs are summarized in Fig. 3. The results obtained with nalidixic acid occupy an intermediate position between those obtained with ampicillin and placebo. Because ampicillinresistant strains often are also insensitive to tetracycline and chloramphenicol, one does not have a satisfactory alternative drug of proven efficacy with which to treat illness due to ampicillinresistant shigellae. Though nalidixic acid therapy results in more rapid elimination of the pathogen than occurs with symptomatic therapy, it has little influence on the course of symptoms, and therefore it cannot be generally recommended for treatment. One might chose, however, to use it for its mitigating effect in severe illness due to multiple-antibiotic resistant strains.

The authors acknowledge the technical assistance of Lula V. Hinton, Edythe B. Woodman, and Sharon L. Shelton. J.D.N. is a recipient of Research Career Development Award 5-K03-11, 650-10 from the National Institute of Allergy and Infectious Diseases.

\section{REFERENCES}

Akbari, A., Ward, J. N., Hilf, M. M., Lavengood, R. W., and Draper, J. W. (1964). NegGram (nalidixic acid) in the treatment of urinary infections. Fournal of Urology, 92, 552.

Barlow, A. M. (1963). Nalidixic acid in infections of the urinary tract; laboratory and clinical investigations. British Medical fournal, 2, 1308.

Bauer, A. W., Kirby, W. M. M., Sherris, J. C., and Turck, M. (1966). Antibiotic susceptibility testing by a standardized single disc method. American fournal of Clinical Pathology, 45, 493.

Carroll, G. (1963). Negram (nalidixic acid): a new antimicrobial chemotherapeutic agent. Fournal of Urology, 90, 476. 
Couston, T. A. (1966). The treatment of sonne dysentery in a closed community. Medical Officer, 115, 147.

Davies, J. R., Farrant, W. N., and Uttley, A. H. C. (1970). Antibiotic resistance of Shigella sonnei. Lancet, $2,1157$.

Farrar, W. E., Jr., and Eidson, M. (1971). Antibiotic resistance in Shigella mediated by $\mathrm{R}$ factors. Fournal of Infectious Diseases, 123, 477.

Fernandez, L. A. (1966). Bacillary dysentery; an institutional outbreak of Shigella sonnei; treatment of thirty-six cases with nalidixic acid. Fournal of the Kansas Medical Society, 67, 359.

Haltalin, K. C., Kusmiesz, H. T., Hinton, L. V., and Nelson, J. D. (1972). Double-blind treatment study of acute diarrhea in outpatients comparing ampicillin and placebo. American fournal of Diseases of Children, 124, 554.

Haltalin, K. C., and Nelson, J. D. (1965). In vitro susceptibility of Shigellae to sodium sulfadiazine and to eight antibiotics. fournal of the American Medical Association, 193, 705.

Haltalin, K. C., and Nelson, J. D. (1972). Failure of furazolidone therapy in shigellosis. American fournal of Diseases of Children, 123, 40.

Haltalin, K. 'C., Nelson, J. D., Hinton, L. V., Kusmiesz, H. T., and Sladoje, M. (1968a). Comparison of orally absorbable and non-absorbable antibiotics in shigellosis. fournal of Pediatrics, 72, 708.

Haltalin, K. C., Nelson, J. D., Kusmiesz, H. T., and Hinton, L. V. (1968b). Comparison of intramuscular and oral ampicillin therapy for shigellosis. Fournal of Pediatrics, 73, 617.

Haltalin, K. C., Nelson, J. D., Ring, R., Sladoje, M., and Hinton, L. V. (1967). Double-blind treatment study of shigellosis comparing ampicillin, sulfadiazine, and placebo. fournal of Pediatrics, $170,9970$.

Jawetz, E. (1962). Assay of antibacterial activity in serum. American fournal of Diseases of Children, 103, 81.
Moorehead, P. J., and Parry, H. E. (1965). Treatment of Sonne dysentery. British Medical fournal, 2, 913.

Nelson, J. D., and Haltalin, K. C. (1966). In vitro susceptibility of E. coli, shigellae and salmonellae to kanamycin and therapeutic implications. Annals of the New York Academy of Sciences, 132, 1006.

Nelson, J. D., and Haltalin, K. C. (1972). In vitro effectiveness of four cephalosporins against Shigellae and clinical ineffectiveness of cephaloglycin. Chemotherapy, 17, 40.

Nelson, J. D., Shelton, S., Kusmiesz, H. T., and Haltalin, K. C. (1972). Absorption of ampicillin and nalidixic acid by infants and children with acute shigellosis. Clinical Pharmacology and Therapeutics, 13, 879.

Pesigan, T. P., and Medado, P. M. (1964). Clinical evaluation of nalidixic acid in the treatment of shigellosis and salmonellosis. Internal Medicine (Manila), 2, 123.

Ross, S., Controni, G., and Kahn, W. (1972). Resistance of Shigellae to ampicillin and other antibiotics. Fournal of the American Medical Association, 221, 45.

Simon, H. J., and Yin, E. J. (1970). Microbioassay of antimicrobial agents. Applied Microbiology, 19, 573.

Thompson, R. E. M., and Rae, J. (1964). Negram (1-ethyl-7methyl-1, 8-naphthyridine-4-1-3-carboxylic acid): a new antibacterial agent for the treatment of urinary tract infection; report of a trial in general practice. British fournal of Urology, 36, 42.

Yu, P. C., and Chen, H. S. (1965). A clinical study of Wintomylon in the treatment of shigellosis. Acta Paediatrica Sinica, 6, 127.

Correspondence to Dr. Kenneth C. Haltalin, The Department of Pediatrics, The University of Texas Southwestern Medical School at Dallas, 5323 Harry Hines Blvd., Dallas, Texas 75236, U.S.A. 